\title{
Impacts of Integration of Wind and Solar PV in a Typical Power Network
}

\author{
Swarna KSV ${ }^{1, *}$, Arangarajan Vinayagam ${ }^{2}$, Sui yang $\mathrm{Khoo}^{3}$ and Alex Stojcevski ${ }^{4}$ \\ ${ }^{1,2,3}$ Faculty of Science, Engineering and Built Environment, Deakin University, Victoria, Australia \\ ${ }^{4}$ Centre of Technology, RMIT, Vietnam \\ *Corresponding author
}

\begin{abstract}
Integration of solar PV and wind in to the distribution network is one of the most promising challenges of the modern power system networks to meet the growing demand of energy. Analysis of the effects of solar and wind intermittencies in the network are vital to maintain the power quality. Keeping this in view, this research paper focuses on impact analysis study of a typical power network with hybrid generation: solar PV and wind integration to quantify the level of impacts like power variation and voltage variation in the network through load flow analysis. Initially, a typical network model is developed using PSS-SINCAL and load profile analysis has been carried out based on the typical daily load profile and wind/solar profile to verify the power and voltage variations extensively in the network considering different scenarios. Results of this research analysis can be used as guidelines for utility grid to provide regulated and improved quality of energy supply by implementing appropriate planning of generation reserve and other control measures in the network.
\end{abstract}

Keywords-impact analysis; solar PV; wind; load flow; power quality, PSS SINCAL

\section{INTRODUCTION}

Worldwide energy demand has been increasing from past few decades. The substantial rise in energy demand and increased concern about the climatic change issues has eventually dragged the interest of modern power generation and distribution towards Renewable Energies (RE). Among the renewables, wind and solar PV plays a prominent role in meeting the growing energy demand and reducing Green House Gas emissions (GHG) due to their reliability in power conversion and cost effectiveness[1, 2].Australia is well placed to utilise the wind and solar PV technologies in to the grid and from the past five years there had been a rapid growth in the penetration levels seen by the grid[3-5].In addition, large scale integration of wind and solar PV in to grid is one of the potential challenges for modern power system since it rigorously effects the PQ of the system based on the network design and grid connection characteristics. The level of integration of wind and solar PV supplies in distribution networks is materially restricted by the voltage management philosophies that were applied when networks were constructed[6, 7]. The basic potential challenges of the integrated network includes power variation, voltage variations, harmonics reactive power compensation flicker, poor power factor, grid impedance variation[8].

Most of the recent research studies focussed on analysing the impacts of the Grid Connected PV (GCPV) systems and grid connected wind systems to maintain the power flow as per the design standards of the network. For instance, in Australia, Lewis [7] studied the impacts of PV systems in the distribution network and from this case study, it was found that with $78 \%$ PV penetration, the voltage level at the load side was comparable to the voltage at LV distribution transformer maintaining voltage consistency. N.Srisaen and A. Sangswang [9] conducted an extensive research on grid connected PV system with $10 \%$ and $25 \%$ PV penetration levels with respective to the load on distribution side. From this analysis itcan be clearly seen that there was a rise of voltage level of around 0.996 p.u when the penetration level changes from $10 \%$ to $25 \%$ regardless of their installation locations. In addition to the voltage variations, the observed difference between maximum and minimum system losses at $25 \%$ penetration level is in the order of hundred kilowatts compared to tens of kilowatts for the case of $10 \%$ penetration. Berk Rona, Önder Guler[10] enormously analysed the impacts of wind on Turkey power grid and from their case studies it can be effectively confirmed that the role of reactive power control of the wind turbine in maintaining the voltage levels of the network is crucial to maintain the voltage proportionalities as per the installed capacity of the wind turbine. Following this literature, an impact analysis study has been carried out in this research paper on a typical power network using PSS SINCAL[11] .Both normal and typical disturbance profiles of solar and wind at minute level has been considered to quantify the power and voltage variations in the network.

The following case studies were considered in section II to analyse the results under different possible scenarios; Only grid, grid with solar, grid with wind, grid with wind and solar, grid with only solar disturbance, grid with solar disturbance and normal wind integration, grid with only wind disturbance, grid with wind disturbance and normal solar, grid with integration of both solar and wind disturbance. Section III summarizes the results and discussions followed by conclusion in section IV.

\section{TYPICAL NETWORK MODELLING WITH SOLAR AND WIND}

A typical network model developed in SINCAL with solar and wind integration is shown in Figure 1.The main elements considered in this model are AC in feeder, transformers, PV arrays, wind turbine and load group. "AC in feeder" operating at $66 \mathrm{KV}$ with a short circuit rating of 500 MVA has been considered as a main grid source for the modeled network. Typical line parameters; resistance: $0.692 \mathrm{ohm} / \mathrm{Km}$, inductive 
reactance: $0.131 \mathrm{ohm} / \mathrm{Km}$, and capacitance:7.03 nf / Km has been considered for building a 22KV network. The specification details of main transformer (MTX), distribution transformers with respective to wind turbines and solar PV (DTX-A, DTX-B), and specification of solar PV, wind turbine and LV load groups are shown in Table 1 and Table 2 respectively. In addition to these network elements, a shunt capacitor with 2 MVAR rating has also been considered for reactive power compensation in the network.

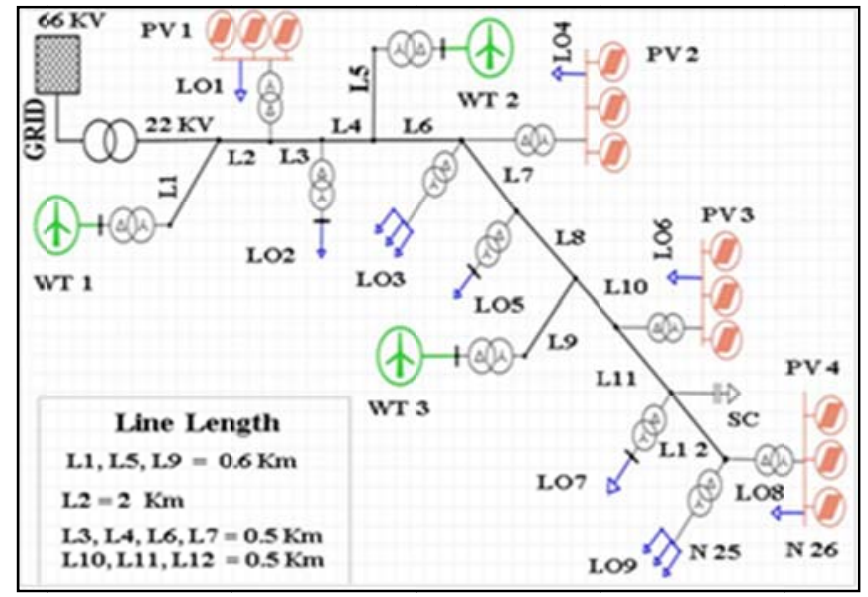

FIGURE I. TYPICAL NETWORK MODEL.

TABLE I. TRANSFORMER SPECIFICATIONS.

\begin{tabular}{|l|c|c|c|}
\hline \multirow{2}{*}{ Transformer } & \multicolumn{3}{|c|}{ Specifications } \\
\cline { 2 - 4 } & $\begin{array}{c}\text { Capacity } \\
\boldsymbol{M V A}\end{array}$ & $\begin{array}{c}\text { Voltage ratio } \\
(\boldsymbol{K V})\end{array}$ & Total number \\
\hline MTX & 32 & $66 / 22$ & 1 \\
\hline DTX-A & 5 & $0.69 / 22$ & 3 \\
\hline DTX-B & 2 & $22 / 0.415$ & 9 \\
\hline
\end{tabular}

TABLE II. DETAILS OF RE SOURCES AND LOAD GROUPS.

\begin{tabular}{|l|c|c|c|}
\hline Element & \multicolumn{3}{|c|}{ Specification } \\
\hline Power factor & Rating of each group & $\begin{array}{c}\text { Total } \\
\text { numbers }\end{array}$ \\
\hline $\begin{array}{l}\text { Wind } \\
\text { Turbine }\end{array}$ & 1 & $0.3 \mathrm{MW}$ & 4 \\
\hline Load & 0.9 & $2.2 \mathrm{MVA}$ & 3 \\
\hline
\end{tabular}

From the Figure 1 it can be noticed that, node N25 is a solar PV bus node close to the far end feeder and node N26 is the extreme end node in the network. For this research study, voltage level during normal operation (normal wind and solar profile) and voltage variation during disturbance (solar and wind disturbance) have been quantified at nodes N25 and N26, since the minimum level of voltage can be expected during the peak load condition at these nodes.

\section{A. Solar PV (Operating Unity Power Factor)}

In this study, each PV unit with a rating of $100 \mathrm{KW}$ has been considered for respective PV groups and also solar PV inverters has been considered to operate at unity power factor, since they do not participate in voltage control in distribution network.

\section{B. TYPE 3 Wind Turbine (Reactive Power Capability)}

Wind turbine using double fed induction generator (DFIG) also called Type 3 turbine is becoming a popular and interesting concept for current researchers due to its improved power quality, controllability and higher efficiency. During no real power generation scenarios-when the wind turbine is not operated, some of the Type 3 wind turbine generators has the ability to deliver the reactive power at the terminals of the wind machine [12]. In this study, Type-3 wind generator has been considered with reactive power compensation of power factor (0.9 lagging to 0.9 leading) cum voltage control facility.

\section{RESUlTS AND DISCUSSIONS}

Using Newton Raphson method, power flow analysis has been extensively carried out according to the daily load, solar and wind profiles for the developed model. Power and voltage level variations had been analyzed at different scenarios as stated above.

\section{A. Impacts under Normal Solar and Wind Profile Conditions}

During peak load condition, voltage and power variations are analysed for the following scenarios: only grid, grid with solar, grid with wind, grid with solar and wind. The detailed results from the simulation shown in Table 3 are discussed in the following section.

TABLE III. GRID POWER AND Node VOLTAGes For FIRST Four CASES.

\begin{tabular}{|c|c|c|c|c|c|c|}
\hline \multirow{2}{*}{ Case Study } & \multicolumn{4}{|c|}{ Grid Power and Node voltage } \\
\cline { 2 - 7 } & \multicolumn{2}{|c|}{ Grid Power } & \multicolumn{2}{c|}{ Wind turbine } & \multicolumn{2}{|c|}{$\begin{array}{c}\text { Node } \\
\text { Voltage } \\
\text { (\%) }\end{array}$} \\
\cline { 2 - 7 } & KW & KVAR & KW & KVAR & N25 & N26 \\
\hline Only Grid & 5550 & 1000 & NA & NA & 96.2 & 94.7 \\
\hline Grid with Solar & 5550 & 1000 & NA & NA & 96.2 & 94.7 \\
\hline Grid with wind & 1500 & 0 & 4050 & 1000 & 98.7 & 97.4 \\
\hline $\begin{array}{c}\text { Grid with Solar } \\
\text { and wind }\end{array}$ & 1500 & 0 & 4050 & 1000 & 98.7 & 97.4 \\
\hline
\end{tabular}

* Solar power is not shown in the table as the simulations were considered during peak load condition

From the simulation results it can be clearly seen that during "only grid" condition the active and reactive power from the grid side was observed to be $5550 \mathrm{KW}$ and $1000 \mathrm{KW}$ respectively with a contribution of 2000 KVAR from the connected shunt capacitor in the network. Similarly during this condition, the voltage level at N25 and N26 were observed to $96.2 \%$ and $94.7 \%$ respectively. The voltage variations with "only grid and grid with wind" are shown in Figure 2.The observed voltage level were same during grid with solar condition as there is no contribution of active power from PV side during peak load (18:00) since there is no sunshine. During "grid with wind" condition, the observed active and reactive power supply from grid was reduced to $1500 \mathrm{KW}$ and $0 \mathrm{KVAR}$ respectively as compared to only grid condition as shown in Figure 3. However, the voltage levels from N25 and N26 were improved by $2.5 \%$ and $2.7 \%$ respectively. This is due to the effect of active and reactive power contributions from all the three wind turbines in the network. For "grid with 
solar and wind" condition, the observed power from the grid side and voltage level at LV bus nodes were same as above condition.

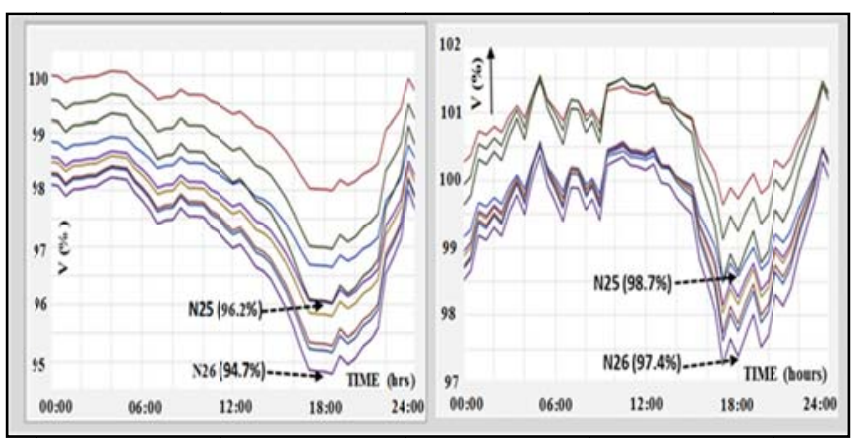

FIGURE II. VOLTAGE VARIATIONS WITH “ONLY GRID “AND “GRID WITH WIND”.

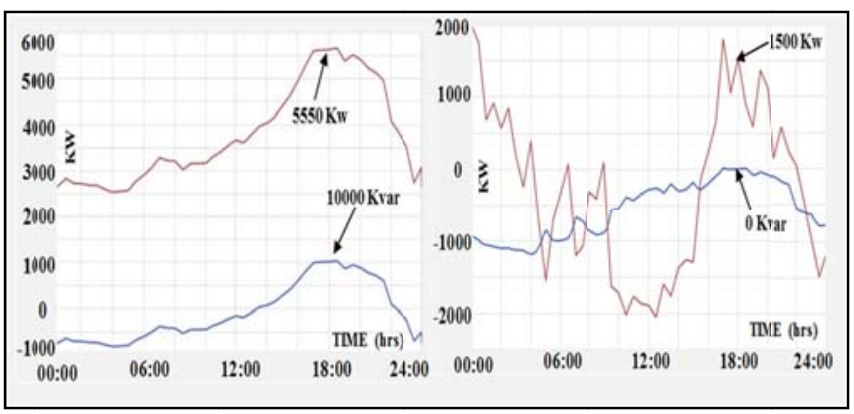

FIGURE III. POWER VARIATIONS WITH “ONLY GRID “AND “GRID WITH WIND”.

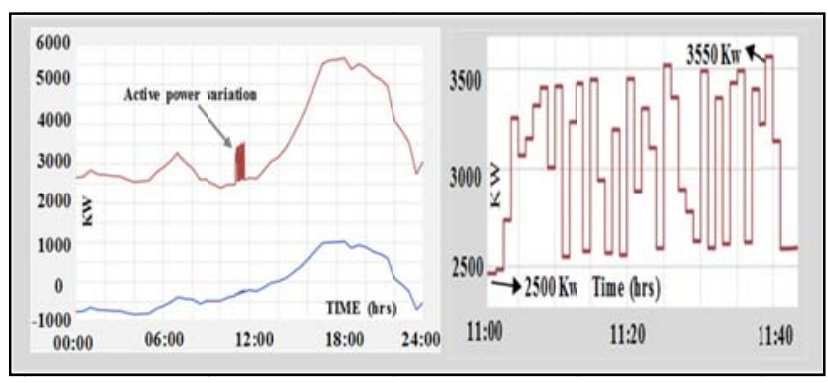

FIGURE IV. VARIATION OF GRID POWER.

\section{B. Impacts in Network During Solar Disturbance}

Minute level variation of solar irradiance effects the regulation of power generation reserve in the network [13]. Keeping this in view, a typical cloud effect of solar disturbance (11:00 to 11:40 hours) varying in minute level has been considered for this analysis and the following power and voltage variations were observed during off-peak time.

1) Power variation: During only solar disturbance condition, it was observed that the output power of each PV unit was varied from a minimum of $0 \mathrm{~kW}$ to a maximum of 82 $\mathrm{kW}$. This cumulative effect of power variations from all the four groups of solar PV creates corresponding effect on active power variation at the grid side. During this scenario, the observed active power of grid was varied from $2500 \mathrm{KW}$ to $3550 \mathrm{~kW}$ and there was a negligible variation of reactive power as shown in Figure 4.However, a variation in reactive power was observed when wind turbines were operated in the network along with this solar disturbance as shown in Figure 5. This is due to the voltage variation caused by solar disturbance and affecting the control behaviour of voltage controller of the wind turbine. The cumulative effect of reactive power variations from all the three wind turbines creates a variation in the export level of reactive power at grid side ranging from $900 \mathrm{KVAR}$ to $1850 \mathrm{KVAR}$.

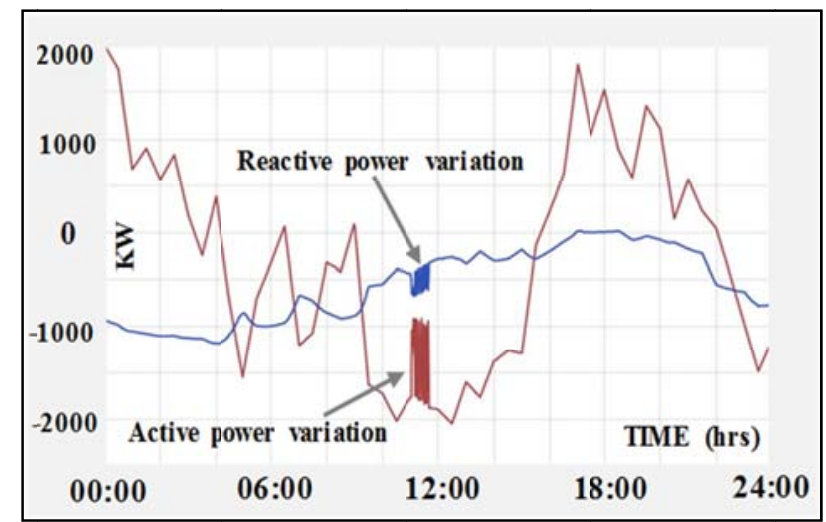

FIGURE V. GRID POWER WITH SOLAR DISTURBANCE AND NORMAL WIND.

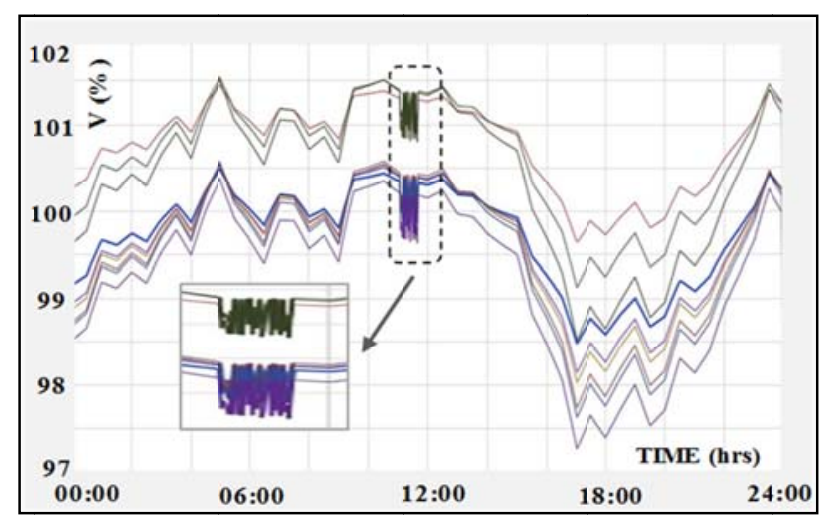

FIGURE VI. VOLTAGE VARIATIONS AT LV NODES.

2) Voltage variation: Figure 6 shows the observed voltage variations at LV nodes during solar disturbance condition. The active power variation from solar PV disturbs the flow of reactive power in the network. Due to this phenomenon, a local voltage variation was observed at solar PV connection point. For instance, the observed minute level voltage variation at the far end of the feeders at bus node N25 and N26 were varied from $98.25 \%$ to $99 \%$ and $97.1 \%$ to $97.83 \%$ respectively. In addition to the solar disturbance when wind turbines were operated in the network, apparently the voltage level was improved with a range of $99.62 \%$ to $100.8 \%$ at bus node N25 and $99.62 \%$ to $100.8 \%$ at bus node N26 respectively.

\section{Impacts in Network during Wind Disturbance}

Due to the intermittent nature of the wind, power generation of the wind turbine varies strongly with time over a wide range of time scales. From [14] it can be seen that "the 
wind power production varies very little in time frame of seconds, more in time frame of minutes and most in time frame of hours". In this analysis, a minute level disturbance (11:00 hours to 11:40 hours) has been considered and the respective power and voltage level has been quantified in the network during off peak period.

1) Power variation: During this case study, the active power variation of each wind turbine was varied from $170 \mathrm{~kW}$ to $1480 \mathrm{~kW}$ as shown in Figure 7. From this scenario it can be evident that the active power variation of each wind turbine is in significant level as compared to the reactive power variation since the output power of wind turbine is greatly proportional to the wind speed [14]. Apparently, this cumulative effect of power variation from all three wind turbines affects the corresponding active power flow variation in grid side ranging from $900 \mathrm{KW}$ to $3000 \mathrm{KW}$ and reactive power flow from -350 KVAR to -700 KVAR, considering minute level profile. The overall grid power variation for 24 hours profile is depicted in Figure 8. However, when solar PV elements were connected in the network with normal solar profile, the observed active power at the grid side was varied from $-1800 \mathrm{KW}$ to $200 \mathrm{KW}$.

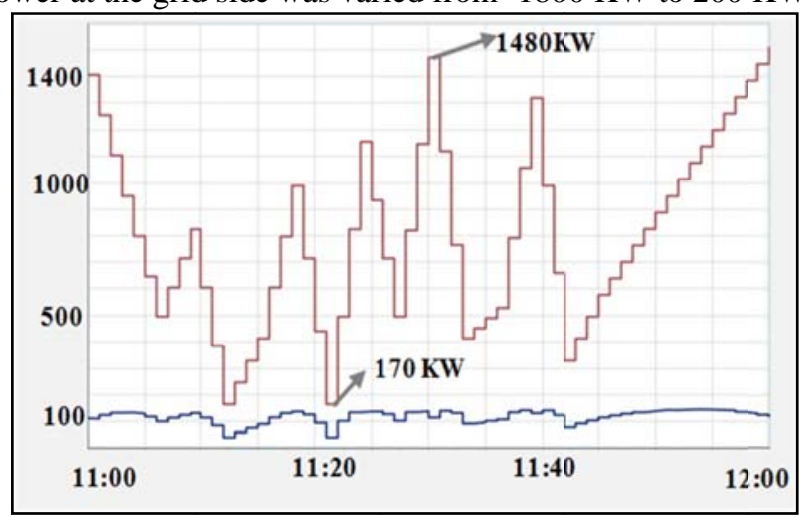

FIGURE VII. POWER VARIATIONS-WIND TURBINE.

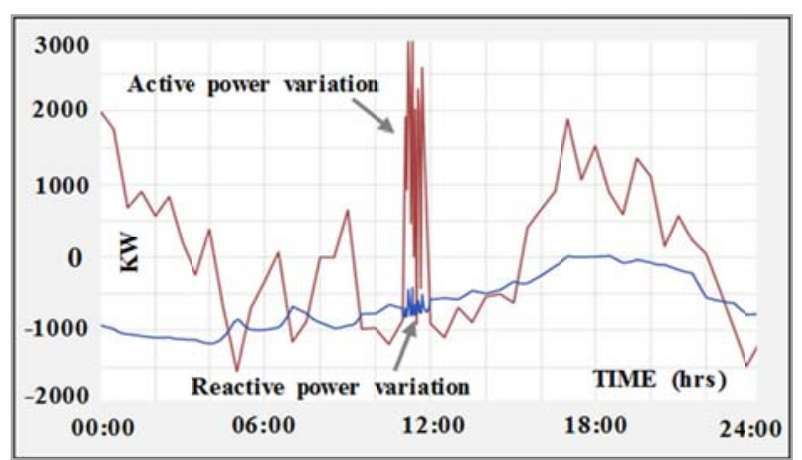

FIGURE VIII. GRID POWER VARIATIONS.

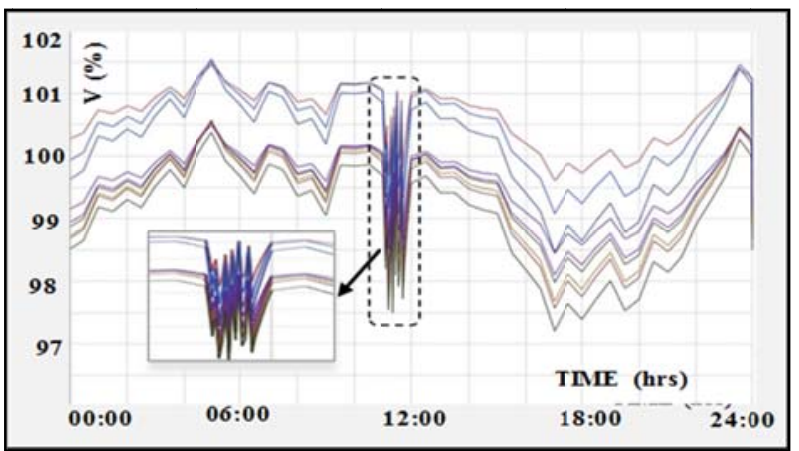

FIGURE IX. VOLTAGE VARIATIONS AT LV NODES.

2) Voltage variation: The variation of active power of each wind turbine affects the reactive power flow and results in local voltage variations at LV bus nodes as shown in Figure 9. The voltage level at node N25 and node N26 were observed to be varied from $97.8 \%$ to $99.8 \%$ and $97.5 \%$ to $99.6 \%$ respectively. However when solar PV modules were connected in the network an improvement in the voltage level was observed .The observed voltage variations from N25 and N26 were varied from $98.2 \%$ to $100.2 \%$ at N25 and $99.3 \%$ to $101.3 \%$ respectively.

\section{Impacts during both Solar and Wind Disturbance}

Considering both solar and wind disturbance at the same time (11:00 hours to 11:40 hours) power and voltage variations were analysed in this scenario .

1) Power variation: During solar disturbance, total active power variation from all four PV groups was observed to be varied from a minimum of $0 \mathrm{Kw}$ to a maximum of $984 \mathrm{KW}$ whereas there was no variation in reactive power since all PV's are considered to operate in unity power factor in network. Similarly, due to the effect of wind disturbance the overall active power and reactive power variation from all the three wind turbines was observed to be varied from $510 \mathrm{KW}$ to $4410 \mathrm{KW}$ and $133 \mathrm{KVAR}$ to $482 \mathrm{KVAR}$ respectively. This is due to the effect of solar disturbance creating a variation in the local voltage level and affecting the behaviour voltage controller of the wind turbine.

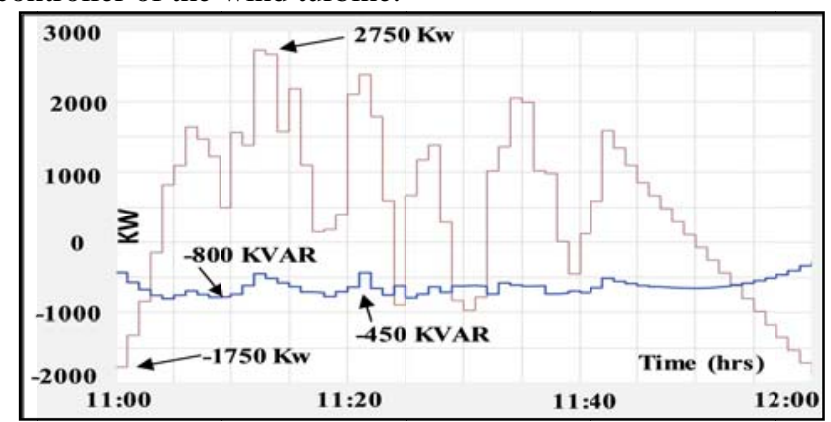

FIGURE X. GRID POWER VARIATIONS MAXIMUM AND MINIMUM. 


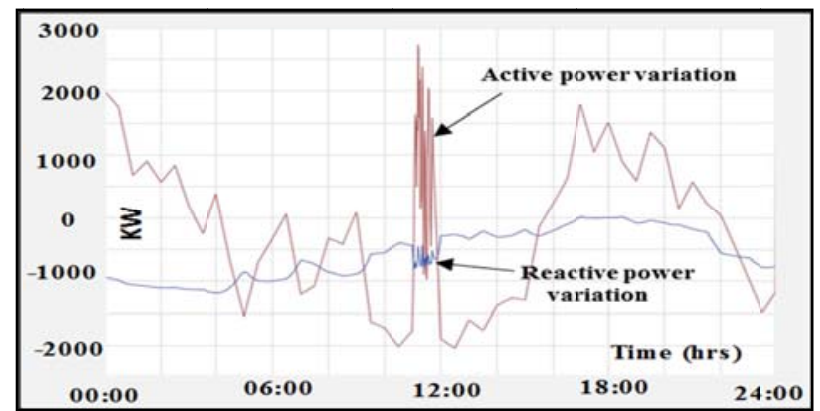

FIGURE XI. OVER ALL GRID POWER VARIATIONS.

Due to this combined effect of active and reactive power variations from solar PV and wind turbine the corresponding effect in grid power variation was observed to be varied from $1750 \mathrm{KW}$ to $2750 \mathrm{KW}$ and $-450 \mathrm{KVAR}$ to $-800 \mathrm{KVAR}$ as shown in Figure 10. Figure 11 shows the overall grid power variations. This power variation affects the regulation of energy supply and creates a situation for immediate requirement of power generation reserve at utility side.

2) Voltage variation: The contribution of reactive power from all three wind turbines improves the voltage level at LV bus nodes. In addition to the voltage level improvement ,the observed voltage variation at N25 and N26 was around 99.1\% to $100.9 \%$ and $97.8 \%$ to $99.8 \%$ respectively. This is due the combined effect of short term solar and wind disturbance in network.

\section{CONCLUSION}

This research paper extensively analyses the power flow in a typical distribution LV network integrated with solar and wind during peak load condition. From the result analysis it can be concluded that by considering normal solar and wind profile condition, when wind turbines were operated in the network the voltage levels at far end of the feeder can be improved where as the active and reactive power contributions at grid side can be reduced. In case of "grid with solar disturbance" condition, an active power variation was noticed from each PV element and grid side resulting voltage variations at LV bus nodes. In case of "grid with solar disturbance and normal wind condition", reactive power variation was observed from each wind turbine resulting a corresponding effect on reactive power flow variation in grid side. In case of "grid with wind disturbance condition", high level of active power variation was depicted from each wind turbine as compared to reactive power variation resulting a corresponding effect of power variations (active and re-active) powers at grid side and voltage variations at LV bus nodes. In case of both "grid with solar and wind disturbance" condition, the active and reactive power variation from wind turbine and active power variation from solar PV creates a corresponding effect power variation in grid side and apparently results in voltage variations at LV bus nodes.

Results of this analysis can be used as guidelines for utility grid to provide regulated and improved quality of energy supply by implementing appropriate planning of generation reserve and other control measures in the network. However, further investigation is required on the effects of large-scale integration of RE in to network for smooth and safe regulatory power flow. Hence, this basic study can be used as a reference to further investigate the large network model with the addition of storage considering the real time network data.

\section{REFERENCES}

[1] A. Akella, R. Saini, and M. Sharma, "Social, economical and environmental impacts of renewable energy systems," Renewable Energy, vol. 34, pp. 390-396, 2009.

[2] G. Boyle, Renewable energy: OXFORD university press, 2004.

[3] D. Mills, "Renewable energy in Australia," Energy \& Environment, vol. 11, pp. 479-509, 2000.

[4] T. M. Jackson, G. R. Walker, and N. Mithulananthan, "Integrating PV systems into distribution networks with battery energy storage systems," in Power Engineering Conference (AUPEC), 2014 Australasian Universities, 2014, pp. 1-7.

[5] T. Ackermann, Wind power in power systems vol. 140: Wiley Online Library, 2005.

[6] Z. Bie, G. Li, H. Liu, X. Wang, and X. Wang, "Studies on voltage fluctuation in the integration of wind power plants using probabilistic load flow," in Power and Energy Society General Meeting-Conversion and Delivery of Electrical Energy in the 21st Century, 2008 IEEE, 2008, pp. 1-7.

[7] S. Lewis, "Analysis and management of the impacts of a high penetration of photovoltaic systems in an electricity distribution network," in Innovative Smart Grid Technologies Asia (ISGT), 2011 IEEE PES, 2011, pp. 1-7.

[8] E. Demirok, D. Sera, R. Teodorescu, P. Rodriguez, and U. Borup, "Clustered PV inverters in LV networks: An overview of impacts and comparison of voltage control strategies," in Electrical Power \& Energy Conference (EPEC), 2009 IEEE, 2009, pp. 1-6.

[9] N. Srisaen and A. Sangswang, "Effects of PV grid-connected system location on a distribution system," in Circuits and Systems, 2006. APCCAS 2006. IEEE Asia Pacific Conference on, 2006, pp. 852-855.

[10] B. Rona and Ö. Güler, "Power system integration of wind farms and analysis of grid code requirements," Renewable and Sustainable Energy Reviews, vol. 49, pp. 100-107, 2015.

[11] SIEMENS PSS SINCAL. Available: http://www.simtecgmbh.at/sites_en/sincal.asp

[12] AEMO. AEMO Wind Integration Studies-2013. Available: http://www.aemo.com.au/Electricity/Planning/Integrating-RenewableEnergy

[13] CSIRO. Solar Intermittency: Australia clean energy challenge2013.Available: https://publications.csiro.au/rpr/download?pid=csiro:EP121914\&dsid=D S1

[14] W. Tong, Wind power generation and wind turbine design: Wit Press, 2010. 